\title{
A Study into Knowledge Management and E-Learning in Educational Organizations
}

Negin jabbary

Assistant professor, Department of Educational Management, Gorgan Branch, Islamic Azad University, Gorgan, Iran

Masoud Piri Tosanloo

Member of Sari City Council \& Ph.D. Student in Public Management, Adalat University, Tehran, Iran

Kazemi-Malekmahmoudi Shima*

Health Management and Social Development Research Center, Golestan University of Medical Sciences, PhD student of Education Management, Islamic Azad University, Gorgan Branch, Gorgan ( ${ }^{*}$ Corresponding author)

Keikha Zahra

M.A. in Education Management, Islamic Azad University, Sari Branch, and Official Educational Mentor of Education Department District, Zahedan

\author{
Doi:10.5901/mjss.2016.v7n3s3p248
}

\begin{abstract}
In the information age, knowledge is considered the key to success. In the modern world, productivity consists in managers' ability to create new scopes of knowledge and stimulate smart activities. The development of information and communication technology and the exponential increase of information and knowledge about the use of modern communicative and information devices including computer have made it essential for educational institutions and universities which are the cradle of education and knowledge production as well as knowledge and professional workforce of a society. With the introduction of computer to human life in parallel with the spread of the internet, many social concepts and services have changes and been moving toward a radical development as the effects of the developments are manifested in the everyday life more and more. In this respect, knowledge management seems essential in order to generate boundless enthusiasm for moving toward E-learning and organizational capacity improvement. In this paper, the function and necessity of E-learning and knowledge management in organizations are addressed.
\end{abstract}

Keywords: E-learning, knowledge management, educational organizations

\section{Introduction}

In the new economy, knowledge is the key produced capital. Massive network of information, virtual institutions and associations and distance education are believed to be the greatest achievements of science and technology development, which can be accomplished by E-learning, and knowledge management and sharing (Kazemi et al, 2014). Approaches to knowledge fall into two categories; systematic and human-centered. The former is consistent with the views of scientists about knowledge as perceived identity. Meanwhile, the latter is in agreement with the views of scientists suggesting that knowledge is an organizational capital. In "knowledge-based theory", Zack (1999) views knowledge as a strategic resource. In educational organizations and universities, the capacity of knowledge management can exert remarkable effect on innovation in individuals' performance by ensuring the suitable application of human skills and capital knowledge. Most business executives hold belief about the capabilities of computers and communicative technologies with respect to knowledge management. They argue that E-learning can create a wealth of saved information in the old and new resources of "knowledge". Other researchers believe that knowledge exist in human mind, as training employees and generating motivation are considered the factors in managing it. Spender came up with opportunities for developing a dynamic knowledge-based theory in organizations. The systematic approach is to set value for knowledge and represents tumultuous organizational fact in the modern world (Spender and Marr, 2005), which makes it essential for organizations to pursue E-learning. It seems that the capacity of knowledge management can assume a determining role between factors of E-learning preparation and innovation in performance. 


\section{E-learning}

With the introduction of computer to human life in parallel with the spread of the network, many social concepts and services have changes and been moving toward a radical development as the effects of the developments are manifested in the everyday life more and more. The virtual world is the magnum opus of the third millennium in human civilization. A vast network of information, major economic enterprises and stores, powerful information search engine, virtual institutions and associations are believed the greatest achievement of E-learning.

The term E-learning was first put forward by Kerass, referring to a variety of learnings which tap into internet and intranet technologies for the purpose of learning. Copper (2004) holds that E-learning is a set of educational activities undertaken by using electronic instruments such as audio, video, and computer and network devices. The definition of Elearning concept is an active and smart learning which takes on a crucial role in developing and deepening and stabilizing the culture of information and communication technology, as well as developing learning-teaching process. E-learning is a mix of three areas; knowledge, education, information technology and management. As for education area, some issues namely nurturing method, educational design, needs assessment, learning styles, etc., have been raised, which is hard to have hope for the success of learning project without regard to these issues (H Khan, 2011).

By E-learning, we general mean the application of electronic systems such as computer, Internet, multimedia CD, electronic journals, and virtual newsletters, which can be accomplished by aiming at reducing commute, saving time and money as well as better and easier learning (Niazazari et al, 2010). The term "E-learning" is an umbrella term that encompasses a vast range of applications, procedures, as well as terms such as "web-based learning, "computer-based learning", "virtual learning environment", and "electronic collaboration".

\section{Necessity of E-learning}

The major aim of E-learning is to overcome limitations namely geographical, cultural, economic, individual, as well as those of common educational systems. The key features of E-learning can include full control over content, fair look at seekers of knowledge, flexibility and tolerance, audience categorization, and free learning. Among the most important advantages of E-learnings, we can refer to generating motivation and interest, identifying priorities in choosing scientific field, central understanding, writing and maintaining educational materials, continuity, reviewing and identifying standpoints, and questioning.

In the technology development-based age and the increase and share of knowledge, E-learning items are presented below for the survival and promotion of educational organizations:

1. Strengthening and encouraging the spread and adoption of digital literacy.

2. Improving individual capabilities for the application of new technologies for the purpose of learning and job.

3. Matching up system of learning and teaching in order to keep pace with the challenges of information society (Mohseni, 2007).

The necessity of E-learning is inevitable for some groups, business, and local communities. The most important groups benefitting from E-learning are those living in remote areas, women and girls, people with disability, people outside school, and employees and workers.

\section{Major challenges and infrastructures in E-learning}

In the research on E-learning, dealing with contextual and cultural factors takes on importance as a key factor due to the transcultural nature of the Web and the breakdown of geographical boundaries. However, we should bear in mind that the phenomenon comes with a lot social and cultural consequences. Isolated learners issue and distance between learners and society is an instance of the consequences. The truth is that face-to-face interaction would guard human modes and reactions, or else interaction cannot take place; this may lead to the isolation and cultural chasm individual and society, which is manifested more in educational organizations, the most important goal of which is to generate and maintain cultural and social capital and to pass it down to next generations. Therefore, it can be claimed that the important challenges confronting this kind of learning in educational organizations are learner's comfort and concentration, farreaching face-to-face and close communication with professor, coherence and avoidance of dispersion, as well as emphasis on theoretical education. Furthermore, the essential infrastructures should not be dispensed with in this regard; if so, the challenge confronting the learning will be doubled. The most important infrastructures of E-learning include:

1. Development of information and communication technology skills at all levels of society for the public;

2. Encouragement and promotion of learning research in the field of information technology; 
3. Competition that gives rise to the quantitative and qualitative expansion of educational software programs;

4. Equipping schools and universities with computers and access to the Web;

5. Developing educational centers for information and communication skills;

6. Strengthening the infrastructure of the Internet in the country

7. Developing the level of public access to computers and the Web

8. Promoting the culture of information technology use in everyday activities (Farhadi, 2005).

\section{Concept of knowledge management}

Knowledge management, knowledge acquisition, intellectual capabilities and experiences of people in organization and retrieval capabilities for them are considered as organizational capital. In other words, necessary procedures are used to identify and glean data, information, and knowledgenecessary for organization through internal and external environment and transferring them in organizational decisions and actions. Hee Han and Park (2009) considered knowledge management system a kind of information system which deals with organizational knowledge management. In effect, knowledge management system is developed to support and strength the processes creation, store, retrieval, and application of knowledge in organization. Davenport (1998) enumerated four goals as the goals of knowledge management:

1. Creating knowledge repository and source

2. Facilitating and improving the access to knowledge and its distribution

3. Strengthening knowledge environment

4. Effectively running knowledge as an asset

\section{Knowledge levels and process of knowledge management}

Knowledge production in educational organizations takes place at three levels: individual level at which employees are the main cause of creating store and use of knowledge in organization, group level at which formal and informal networks and groups of employees who share experiences are included, the third level, organizational level at which the entire organization is consideredas a set of knowledge (Razi and Samiiee, 2012). Knowledge cycle, i.e. process of knowledge management, consists of four main parts: in the first stage, it is imperative to identify knowledge available at organizational level and its obstacles (both individual's explicit and tacit knowledge, information bank, documents), and then they are acquired and kept appropriately. Afterward, in order to allow the valued knowledge to multiply and regenerate knowledge, individuals' knowledge should be shared. Following these steps, it is time to utilize the acquired knowledge for higher purposes of organization. Knowledge production include new information entering system and is the upshot of knowledge sharing among individuals. It also includes acquisition, exploration, and development of knowledge.Choee et al (2003) dealt with knowledge approaches in two categories; systematic approaches and humanfocused approaches. The former is consistent with the perspectives of scientists with respect to knowledge as a perceived identity, while the latter is in agreement with the views of scientists about knowledge functioning as organizational asset. According to Zack, knowledge-based theory sees knowledge as a strategic source (Zack, 1999). Spender offers a series of opportunities for the development of the future of knowledge-based theory in organization. It is a systematic approach generating value for knowledge that implies the turbulent organizational truth in the modern world (Spender and Marr, 2005).

\section{Implementation of knowledge management in educational organizations}

The concepts of knowledge management need to communicated to staff; in doing so, it is necessary to require the consent and cooperation of senior organizational leaders and managers so as to implement this kind of management successfully, because success or failure of a project depend largely on the support of these individuals. However, the culture of knowledge sharing definitely consists in the attitude of people who built the culture. In case employees show no desire to share their knowledge with one another, it will be extremely difficult to promote the culture of knowledge sharing among them through rewarding system or legal requirements. As a matter of fact, it is the senior organizational leaders and managers of educational organizations who are assigned to make the entire resource of organization aligned with idealistic and purposeful ideas, large-scale outlook and picture of futureand put them in the same order. Customer orientation, respect for educational clients and learners, listening to client's, learner's voice, watching individual's present and future expectations, offering the best performance of organizational goals realized, etc., are part of the culture and 
goals of educational organizations. Hence inparallel with the managerial goals, the effort is made to change individual learning into team and organizational learning. Since knowledge is conceived of as the most strategic resource of educational organizations, in order to implement knowledge management and E-learning, it is necessary for intelligent, alert and determined managers to be chosen so as to create knowledge from information and experience, attempting to distribute it throughout organization.

Success in the planning of knowledge management in organization depend on the direct support, commitment of senior management and leadership of organization. A knowledge management programs require the support of senior management so that they can thrive during design procedures and implementation. Moreover, the contemporary need of organizations is directed toward knowledge-focused structures, which are non-hierarchical and flat and they are processoriented rather than duty-oriented; knowledge production and knowledge sharing happen inside organizational structure. Since the intellectual assets of organization lie in the minds of staff, education and nurture of knowledge-oriented human resource are considered the important infrastructure of knowledge management in order to develop and expand knowledge and the ability to create and regenerate new ideas. It should not be assumed that knowledge management is comprised of a set of software programs and hardware which deals with production, maintenance, and documentation of knowledge. Cultural challenges such as the culture of knowledge hoarding may cause the whole project to end in failure. Thus, building open and space and trust orientation in an attempt to provide the suitable cultural foundations and infrastructures and knowledge-based organizational culture is obviously essential for sharing knowledge. It should be thus noted that technology infrastructure pave the way for the fast and timely access to information. At the time of shaping organizational memory and documenting organizational experiences and skills, as well as sharing organization, the path to learning organization creation can be reached by removing geographical distances (Sharifzadeh, 2003).

\section{Relationship between E-learning and knowledge management}

Educational organizations are required to provide different and inexpensive methods, especially E-learning, in order to make it possible the more efficient use of professors, teachers, and employees, improvement of their knowledge and skills. For organizations, application of participation through knowledge management is very crucial. Organizations which utilize E-learning as part of learning strategy will reach capabilities which are hard to be achieved by attending class. It is true that E-learning can reduce costs of organization and allow for education in every place any time in a week, but the real value of E-learning is embedded in its ability in the integration of work procedures into the expansion of spiritual capitals in organization. Organization can mechanize learning offering by using E-learning and offer personalized training to staff. Moreover, using miscellaneous instruments can make it much easier to glean and distribute dispersed knowledge in organization.

In the research conducted in order to recognize approaches and instruments that allow for the greatest use in implementing knowledge management, E-learning has the greatest contribution to knowledge management subsequent to organizational universities (Antonova et al, 2006). For this reason, the suitable foundationfor implementing E-learning influenced by a variety of factors including cultural factors, environmental factors, infrastructural and financial and technical team is provided. Organizations can make use of the factors in order to make organization more thrive in applying E-learning effectively. Raising employees with knowledge and expertise is very crucial to organizations in order to fulfil activities and act by knowledge management instrument. Indeed, E-learning and its factors are considered the key elements to organizations in order to increase capacity and to facilitate the means of knowledge management. Benefitting from financial resources and facilities necessary for making basic investment such as costs of facilities, expert resource, training employees etc. would encourage organization managers to improve knowledge sharing. In the end, it can be claimed that the foregoing factors can support and promote knowledge management activities. Therefore, it is expected that infrastructures of E-learning positively influence the capacity of knowledge management in educational organizations and universities.

\section{Conclusion}

In contemporary educational organizations, productivity consists in the ability of managers to create new knowledge and start smart activities. Development of information and communication technology and the exponential increase of information and knowledge, the use of modern communicative and information devices including computer have become essential for educational organizations and universities serving as the cradle of education and knowledge production and knowledgeable and professional workforce for society. E-learning and knowledge management carry out a function with a variety of methods. It saves a specialist's expertise, putting it in the process of educational design and offering the result 
within a certain framework. On the other hand, knowledge management comes up with raw knowledge with little process. Thus, it can be claimed that E-learning and knowledge management seek the same subject; facilitating learning in organization, though E-learning in educational organizations together with conventional and traditional learning can contribute more effectively to the communication and production of knowledge. Therefore, as the pattern of information exchange changes, managers can avail themselves of knowledge in order to yield competitive benefit to organization and realize educational goals at employee, teacher, and learner level, ensuring the possibility of their remaining and promotion in the global village.

\section{References}

Bedrol, H.Khan. (2011). Management of E-learning. Translated by Ghaeni, E.

Abdhagh, B. Publisher: Industrial Management Organization, $1^{\text {st }}$ edition.

Piri, M. Karimi, F. and Kazemi, Sh. (2015). Generations of Knowledge Management and Organizations; an international conference on the role of the Islamic Revolution's management in the geometry of the power of the world system (Management, Policy, Culture, Security, Economy, Accounting), Tehran.

Sharifzadeh, F. (2008). Knowledge management in administrative, manufacturing and service organizations. Jihad Daneshgahi. $1^{\text {st }}$ edition, AllamehTabatabai University.

Davenport and Prusak. (2002). Knowledge management. Daneshkar Press.

Farhadi, R. (2005). E-learning: new paradigm in the age of information. View: E-journal, No. 1, 21stvol, retrieved fromhttp://www,irandoc.ac.ir/data/vol21.

Jaafari, A. (2005). Knowledge management. Scientific-Professional Journal of Tadbir, No. 171

Jabari, N. and Kazemi, Sh. (2014). Knowledge management, an outlook of successful organizations; the second international conference on Management of Challenges and Strategies, Shiraz.

Mohseni, M. (2007). Sociology of information society. Tehran: Diar Press

Antonova, A. \&Gourove, e. \&Nikolov, R. (2006). Knowledge management and learning in the organizational context, 3rd E-learning Conference Coimbra, Portugal, 7-8 September].Davenport TH, Prusak L. 1998. Working Knowledge. Harvard Business School Press: Boston, MA.

E-learing Strategies How to get implementation and delivery right first time, don Morrison (2003), john Wiley \& Sons Ltd.

Jabari, N. and Kazemi, Sh. (2015). Knowledge management, an outlook of successful organizations; Shiraz Journal of System Management, Special Issues, 171-180.

Hee Han, Kwan \& Park, Jun Woo. (2009). Process-centered knowledge madel and enterprise ontology for the development of knowledge management system. Expert Systems with Applications, 36, 7441-7447 .

McFarlane DA. 2008. Effectively managing the 21st century knowledge worker. Journal of Knowledge Management Practice 9(1): 3-7.

Serenko A, Bontis N, Hardie T. 2007. Organizational size and knowledge flow: a proposed theoretical link. Journal of Intellectual Capital 8(4): 1469-1930.

Spender JC, Marr B. 2005. A knowledge-based perspective on intellectual capital. In Perspectives on Intellectual Capital' 2005, Marr B (ed.). Sage; 183-195.

PiriTosanloo. M, KarimiBirgani. F, KazemiMalekmahmoudi. Sh. 2015. Generations of Knowledge Management and Organizations, Int. J. Rev. Life. Sci., 5(1), 2015, 549-553.

Zack HM. 1999. Developing a knowledge strategy. California Management Review 41(3): 125-145. 